\title{
APLIKASI BIOROCK TERHADAP KELANGSUNGAN HIDUP TRANSPLANTASI KARANG DAN KEANEKARAGAMAN IKAN DI PULAU KARIMUNJAWA
}

\author{
Oleh \\ Sahala Bonardo Siahaan, Pudjiono Wahyu Purnomo*) dan Bambang Sulardiono \\ Program Studi Manajemen Sumberdaya Perairan \\ Departemen Sumberdaya Akuatik Fakultas Perikanan dan Ilmu Kelautan Universitas Diponegoro \\ Jl. Prof. Soedharto, SH Semarang (sahalabonardos@gmail.com)
}

\begin{abstract}
ABSTRAK
Taman Nasional Karimunjawa (TNKJ) merupakan tempat konservasi bagi lingkungan dan biota. Kualitas terumbu karang di Karimunjawa mempunyai keanekaragaman yang tinggi. Ada berbagai teknik yang dapat digunakan untuk merehabilitasi terumbu karang, salah satunya adalah Biorock. Tujuan dari penelitian ini adalah mengetahui kelangsungan hidup dan pertumbuhan karang yang ditransplantasi pada biorock dan mengetahui keanekaragaman ikan yang berada di sekitar biorock. Metode yang digunakan dalam penelitian ini adalah metode eksperimen lapangan di mana terdapat 2 stasiun penelitian. Biorock digunakan sebagai tempat untuk dijadikannya proses transplantasi karang jenis Acropora sp. Pengukuran pertumbuhan karang dilakukan di dalam air dengan periode selama 2 bulan dengan tenggang waktu 1 bulan menggunakan jangka sorong. Untuk mengevaluasi perbedaan perbedaan pertumbuhan dan kelangsunggan hidup setiap spesies yang ditransplantasi mempergunakan uji $\mathrm{t}$ independen. Spesies terumbu karang yang memiliki persentase kelangsungan hidup paling tinggi adalah Acrophora nasuta. Berdasarkan uji t tentangperbedaan kelulushidupan karang stasiun 1 dan 2 menunjukkan bahwa tidak adanya perbedaan yang signifikan $(\alpha>0,05)$. Jenis ikan yang ditemukan pada lokasi penelitian adalah Zanclus sp, Selaroides sp, dan Sigauns sp. Ditemukan pula spesies bulu babi yaitu Diadema sp. Parameter Fisika-Kimia kedalaman, kecerahan, temperatur, $\mathrm{pH}$, dan salinitas pada 2 stasiun sudah memenuhi syarat untuk pertumbuhan karang.
\end{abstract}

Kata Kunci :Biorock, Karang, Karimunjawa

ABSTRACT

Karimunjawa National Park is a conservation area for the environment and biota.There are various techniques that can be used to rehabilitate coral reefs, one of which is Biorock. The purpose of this research is to know the survival and growth of transplanted corals in biorock and to know the diversity of fish that are around the biorock. The method used in this research is the field experimental method. The location of this research consists of 2 research stations. Biorock is used as a place to make its transplant coral process type Acropora sp. Measurement of coral growth measured in water for a period of 2 months with a period of 1 month using a vernier caliper. To evaluate differences in growth and survival of each transplanted species using independent $t$ test. The coral reef species that have the highest survival rate is Acrophora nasuta. Based on the result of t test about difference of coral reef life at station 1 and 2 shows that there is no significant difference between them $(\alpha>0,05)$. Fish species found at the study sites were Zanclus $\mathrm{sp}$, Selaroides $\mathrm{sp}$, and Siganus $\mathrm{sp}$. Also found species of sea urchin is Diadema sp. Physical-Chemical parameters of depth, brightness, temperature, $\mathrm{pH}$, and salinity at 2 stations have included requirements for coral growth.

Keywords : Biorock, Coral, Karimunjawa.

\section{PENDAHULUAN}

Salah satu potensi sumberdaya alam yang melimpah di Indonesia adalah terumbu karang. Luasan terumbu karang Indonesia mencapai $51 \%$ dari luasan di Asia Tenggara, namun prosentasenya mengalami penurunan dari tahun ke tahun, dimana 30,96\% yang masih dalam keadaan baik,sedangkan 69,04\% dalam kondisi buruk (Coremap, 2008). Oleh karena itu, dibutuhkan upaya rehabilitasi agar kondisi terumbu karang dapat pulih kembali.

Pulau Karimunjawa berada di Laut Jawa tepatnya di Kecamatan Karimunjawa, Kabupaten Jepara, Provinsi Jawa Tengah. Taman Nasional Karimunjawa (TNKJ) merupakan tempat konservasi bagi lingkungan dan biota yang terdapat di lokasi tersebut dan memiliki fungsi utama sebagai tempat pelestarian lingkungan dan biota (Wizurai et al., 2012). Pengelolaan dalam upaya pengawetan keanekaragaman hayati Balai Taman 
Nasional Karimunjawa meliputi identifikasi dan inventarisasi, pembinaan habitat, pembinaan populasi dan rehabilitasi dan menyimpan potensi keanekaragaman hayati yang tinggi bahkan terdapat beberapa potensi keanekaragaman hayati yang belum teridentifikasi. Hasil monitoring menunjukkan terjadi degradasi potensi keanekaragaman hayati pada beberapa jenis fauna ekonomis penting, terlihat dari terjadinya penurunan biomassa beberapa jenis ikan ekonomis penting (Balai Taman Nasional Karimunjawa, 2012).

Kehidupan ekosistem terumbu karangdan biota yang hidup di dalamnya seperti polip karang dan zooxanthellae sangat bergantung pada kondisi lingkungan yang ada di perairan seperti suhu, arus/gelombang, kedalaman, oksigen terlarut, $\mathrm{pH}$, salinitas nitrat dan fosfat. Khususnya pada kedalaman, nitrat dan fosfat sangat mempengaruhi densitas zooxanthellae karena intensitas cahaya matahari yang masuk ke perairan sangat mempengaruhi kehidupan zooxanthellae dan zooxanthellae membutuhkan nutrisi agar tetap hidup dan menempel pada polip karang.

Ada berbagai teknik yang dapat digunakan untuk merehabilitasi terumbu karang, salah satunya adalah Biorock. Biorock merupakan teknik terumbu buatan melalui proses akresi mineral dengan menggunakan struktur kerangka kokoh baik yang dilakukan dengan dialiri oleh arus listrik bertegangan rendah maupun secara alamiah dengan menempatkan struktur ke habitat terumbu karang yang rusak. Penggunaan teknologi ini memanfaatkan proses elektrolisis dengan adanya anoda dan katoda sehingga menyebabkan mineral terlarut dalam air laut membentuk endapan padatan mineral yang menempel pada struktur kerangka. Sementara itu biorock alami untuk memastikan dukungan ekosistem terhadap kelangsungan hidup dan pertumbuhan karang yang ditransplantasi secara alamiah. Tujuan dari penelitian ini adalah mengetahui kelangsungan hidup dan pertumbuhan karang yang ditransplantasi pada biorock dan mengetahui keanekaragaman ikan yang berada di sekitar biorock.

\section{METODE PENELITIAN}

Metode yang digunakan dalam penelitian ini adalah metode eksperimen lapangan, yaitu suatu cara untuk mengetahui hubungan sebab akibat dengan cara memberikan satu atau lebih perlakuan dan membandingkan hasilnya untuk dilihat pengaruhnya terhadap obyek penelitian yang dilakukan di lapangan (Nazir, 1988).

Pembuatan biorock digunakan sebagai tempat untuk dijadikan nya proses transplantasi karang jenis Acropora sp. Dengan bahan dasar besi yang sudah berbentuk pola setengah lingkaran dengan ukuran diameter 1 meter. Sketsa Biorock yang ditunjukkan adalah :

Ket : A : Biorock $\frac{1}{2}$ lingkaran bawah B : Biorock $\frac{1}{2}$ lingkaran atas

B

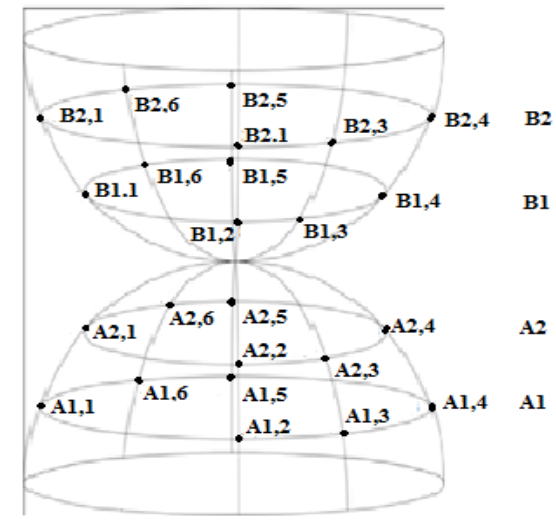

Gambar 1. Bagan Biorock

Lokasi pembibitan adalah dikawasan terumbu karang Karimunjawa. Dalam hal ini dilakukan penanaman terumbu karang dengan menggunakan karang jenis Acropora $s p$. Bibit karang yang sudah didapatkan diikatkan ke sela besi bagan dengan menggunakan perekat.Lokasi penelitian adalah di Pulau Karimunjawa tepatnya di dekat dermaga baru Pulau Karimunjawa. Penentuan lokasi sampling dilakukan di sekitar terumbu karang dengan menempatkan kerangka biorock di kedalaman $150 \mathrm{~cm}$ (stasiun 1) dan $80 \mathrm{~cm}$ (stasiun 2). 


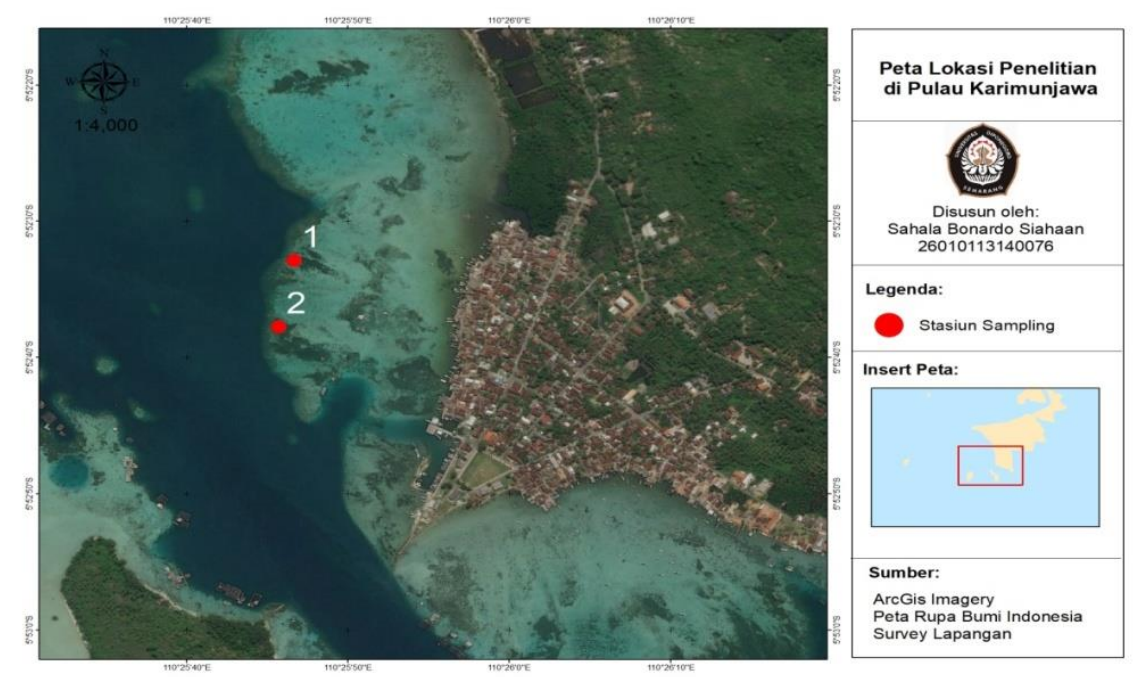

Gambar 2. Peta Lokasi Penelitian

\section{HASIL DAN PEMBAHASAN}

\section{HASIL}

\section{Kelangsungan Hidup Karang}

Penambahan ukuran rata-rata fragmen karang transplantasi memilki nilai yang berbeda untuk setiap spesies. Perbedaan pertumbuhan dikarenakan perbedaan bentuk pertumbuhan karang disetiap spesiesnya serta akibat respon kondisi lingkungannya.Pada penelitian ini terdapat 4 spesies karang yang ditransplantasi, yaitu Acropora nasuta, Acropora macrostoma, Acropora aspera, Acropora austera. Masing-masing stasiun ditemukan mati sebagian ditemukan hidup dan tumbuh. Hasil pengukuran tingkat kelangsungan hidup tersaji pada Tabel 1.

Tabel 1. Persentase Kelangsungan Hidup Karang

\begin{tabular}{ccccccccc}
\hline \multirow{2}{*}{ Spesies Karang } & \multicolumn{1}{c}{ Kelangsungan Hidup } \\
\cline { 2 - 8 } & St-1 & St-2 & St-1 & St-2 & St-1 & St-2 & St-1 & St-2 \\
\hline $\begin{array}{c}\text { Acropora } \\
\text { austera }\end{array}$ & 6 & 6 & 2 & 2 & 2 & 2 & 33,33 & 33,33 \\
$\begin{array}{c}\text { Acropora } \\
\text { macrostoma } \\
\text { Acropora } \\
\text { nasuta }\end{array}$ & 6 & 6 & 4 & 3 & 1 & 2 & 16,66 & 33,33 \\
$\begin{array}{c}\text { Acropora } \\
\text { aspera }\end{array}$ & 6 & 6 & 4 & 4 & 2 & 4 & 33,33 & 66,66 \\
& 24 & 24 & 12 & 15 & 7 & 11 & & 50 \\
\hline
\end{tabular}

Tabel 2. Pertumbuhan Acropora nasuta

\begin{tabular}{ccccccccc}
\hline \multirow{2}{*}{ Posisi Biorock } & \multicolumn{2}{c}{ Mei } & \multicolumn{2}{c}{ Juni } & \multicolumn{2}{c}{ Juli } & \multicolumn{2}{c}{ Pertumbuhan } \\
\cline { 2 - 9 } & St-1 & St-2 & St-1 & St-2 & St-1 & St-2 & St-1 & St-2 \\
\hline A1,1 & 7,1 & - & - & - & - & - & 0 & 0 \\
A1,4 & 6,9 & 5,6 & - & 5,8 & - & 5,9 & 0 & 0,3 \\
A1,5 & - & 5,8 & - & 5,9 & & & 0 & 0 \\
A2,1 & 5,6 & - & 5,6 & - & 5,8 & - & 0,2 & 0 \\
A2,2 & 5,4 & - & - & - & - & - & 0 & 0 \\
\hline
\end{tabular}

${ }^{\odot}$ Copyright by Management of Aquatic Resources (MAQUARES) 


\begin{tabular}{ccccccccc}
\hline A2,4 & - & 5,7 & - & 5,7 & - & - & 0 & 0 \\
A2,6 & - & 5,6 & - & 5,6 & - & - & 0 & 0 \\
B1,2 & - & 5,7 & - & 5,9 & - & 6 & 0 & 0,3 \\
B1,4 & 6 & - & - & - & - & - & 0 & 0 \\
B2,1 & - & 6,2 & - & 6,7 & - & 7,1 & 0 & 0,9 \\
B2,2 & 5,4 & - & 5,4 & - & 5,5 & - & 0.1 & 0 \\
\hline
\end{tabular}

Keterangan : A= Bagan biorock bawah, B = Bagan Biorock atas, n1,n2= lajur a, $\mathrm{n}=$ nomor

Berdasarkan hasil uji t independen pada pertumbuhan karang Acropora nasuta diperoleh kesimpulan bahwa tidak ada perbedaan yang signifikan antara penempatannya pada biorock stasiun 1 dan stasiun $2(\alpha>0,05)$.

Tabel 3. Pertumbuhan Acropora macrostoma

\begin{tabular}{ccccccccc}
\hline \multirow{2}{*}{ Posisi Biorock } & \multicolumn{2}{c}{ Mei } & \multicolumn{2}{c}{ Juni } & \multicolumn{2}{c}{ Juli } & \multicolumn{2}{c}{ Pertumbuhan } \\
\cline { 2 - 5 } & St-1 & St-2 & St-1 & St-2 & St-1 & St-2 & St-1 & St-2 \\
\hline A1,1 & - & 6,7 & - & - & - & - & 0 & 0 \\
A1,2 & - & 7,1 & - & 7,3 & - & 7,4 & 0 & 0,3 \\
A1,6 & 6,6 & - & - & - & - & - & 0 & 0 \\
A2,2 & - & 7,3 & - & 7,4 & - & 7,7 & 0 & 0,4 \\
A2,3 & 7,1 & - & 7,1 & - & 7,2 & - & 0,1 & 0 \\
A2,5 & - & 7,1 & - & - & - & - & 0 & 0 \\
B1,2 & 6,7 & - & - & - & - & - & 0 & 0 \\
B1,3 & - & 6,8 & - & 6,8 & - & - & 0 & 0 \\
B1,6 & 6,4 & - & - & - & - & - & 0 & 0 \\
B2,3 & 6,3 & 6,9 & - & 6,9 & - & - & 0 & 0 \\
B2,6 & 6,5 & - & - & - & - & - & 0 & 0 \\
\hline
\end{tabular}

Keterangan : A= Bagan biorock bawah, B = Bagan Biorock atas, n1,n2= lajur a, $\mathrm{n}=$ nomor

Berdasarkan hasil uji t independen pada pertumbuhan karang Acropora macrostoma diperoleh kesimpulan bahwa tidak ada perbedaan yang signifikan antara penempatannya pada biorock stasiun 1 dan stasiun $2(\alpha>0,05)$.

Tabel 4. Pertumbuhan Acropora aspera

\begin{tabular}{ccccccccc}
\hline \multirow{2}{*}{ Posisi Biorock } & \multicolumn{3}{c}{ Mei } & \multicolumn{2}{c}{ Juni } & \multicolumn{2}{c}{ Juli } & \multicolumn{2}{c}{ Pertumbuhan } \\
\cline { 2 - 9 } & St-1 & St-2 & St-1 & St-2 & St-1 & St-2 & St-1 & St-2 \\
\hline A1,2 & 8,7 & - & - & - & - & - & 0 & 0 \\
A1,3 & 6,8 & 8,4 & - & - & - & - & 0 & 0 \\
A2,1 & - & 8,4 & - & 8,4 & - & - & 0 & 0 \\
A2,4 & 6,8 & - & - & - & - & - & 0 & 0 \\
A2,5 & 7,2 & - & - & - & - & - & 0 & 0 \\
B1,1 & - & 8,4 & - & 8,7 & - & - & 0 & 0 \\
B1,4 & - & 8,7 & - & 8,9 & - & 9,1 & 0 & 0,4 \\
B1,5 & 7,3 & - & 7,4 & - & 7,5 & - & 0,2 & 0 \\
B2,4 & 7,4 & - & 7,5 & - & 7,5 & - & 0,1 & 0 \\
B2,5 & - & 9,4 & - & 9,7 & - & 9,8 & 0 & 0,4 \\
B2,6 & - & 8,3 & - & 8,5 & - & 8,6 & 0 & 0,3
\end{tabular}

Keterangan : A= Bagan biorock bawah, B = Bagan Biorock atas, n1,n2= lajur a, n = nomor

Berdasarkan hasil uji t independen pada pertumbuhan karang Acropora aspera diperoleh kesimpulan bahwa tidak ada perbedaan yang signifikan antara penempatannya pada biorock stasiun 1 dan stasiun $2(\alpha>0,05)$.

Tabel 5. Pertumbuhan Acropora austera 
Aplikasi Biorock Terhadap Kelangsungan Hidup Transplantasi Karang dan Keanekaragaman Ikan

\begin{tabular}{ccccccccc}
\hline \multirow{2}{*}{ Posisi Biorock } & \multicolumn{2}{c}{ Mei } & \multicolumn{2}{c}{ Juni } & \multicolumn{2}{c}{ Juli } & \multicolumn{2}{c}{ Pertumbuhan } \\
\cline { 2 - 8 } & St-1 & St-2 & St-1 & St-2 & St-1 & St-2 & St-1 & St-2 \\
\hline A1,5 & 7,6 & - & 7,6 & - & 7,7 & - & 0.1 & 0 \\
A1,6 & - & 7,5 & - & 7,7 & - & 7,8 & 0 & 0,3 \\
A2,3 & - & 7,6 & - & - & - & - & 0 & 0 \\
A2,6 & 7,4 & - & - & - & - & - & 0 & 0 \\
B1,1 & 7,1 & - & - & - & - & - & 0 & 0 \\
B1,3 & 7,2 & - & 7,2 & - & 7,4 & - & 0,2 & 0 \\
B1,5 & - & 7,4 & - & - & - & - & 0 & 0 \\
B1,6 & - & 8,6 & - & 8,9 & - & 9,2 & 0 & 0,6 \\
B2,1 & 6,9 & - & - & - & - & - & 0 & 0 \\
B2,2 & - & 7,1 & - & 7,2 & - & - & 0 & 0,1 \\
B2,4 & - & 6,9 & - & 6,9 & - & - & 0 & 0 \\
B2,5 & 7,2 & - & - & - & - & - & 0 & 0 \\
\hline
\end{tabular}

Keterangan : A= Bagan biorock bawah, B = Bagan Biorock atas, n1,n2= lajur a, n = nomor

Berdasarkan hasil uji t independen pada pertumbuhan karang Acropora austera diperoleh kesimpulan bahwa tidak ada perbedaan yang signifikan antara penempatannya pada biorock stasiun 1 dan stasiun $2(\alpha>0,05)$.

\section{Keanekaragaman Biota}

Pada pengamatan terhadap biota disekitar terumbu karang ditemukan berbagai macam biota mulai dari ikan karang hingga bulu babi dikedua titik lokasi penanaman bagan transplantasi karang. Pengamatan pertama dilakukan ketika peletakan bagan transplantasi tidak ditemukan biota disekitar lokasi. Dalam pengamatan kedua disekitar bagan kedua lokasi ditemukan Zanclus sp, Siganus sp, Selaroides sp, dan Diadema sp. Selama lamanya pengamatan dua bulan sudah banyak biota yang ditemukan pada lokasi bagan penanaman transplantasi karang terutama untuk jenis Diadema sp yang pertumbuhan populasinya sangat pesat. Diadema sp banyak ditemukan dilokasi titik dua bisa mencapai 14 buah pada bulan juli dibandingkan dengan waktu pertama peletakan bagan transplantasi karang

Tabel 6. Keanekaragaman Ikan

\begin{tabular}{|c|c|c|c|c|c|c|}
\hline \multirow{2}{*}{$\begin{array}{c}\text { Jenis Ikan } \\
\text { yang } \\
\text { ditemukan }\end{array}$} & \multicolumn{2}{|c|}{ Mei } & \multicolumn{2}{|c|}{ Juni } & \multicolumn{2}{|c|}{ Juli } \\
\hline & Stasiun 1 & Stasiun 2 & Stasiun 1 & Stasiun 2 & Stasiun 1 & Stasiun 2 \\
\hline Zanclus sp. & 3 & 5 & 4 & 5 & 2 & 2 \\
\hline Selaroides sp. & 4 & 7 & 4 & 5 & 1 & 1 \\
\hline Siganus sp. & 3 & 4 & 4 & 5 & 0 & 3 \\
\hline Diadema sp. & 0 & 3 & 3 & 11 & 3 & 14 \\
\hline
\end{tabular}

\section{Parameter Fisika-Kimia}

Parameter fisika kimia perairan merupakan faktor pendukung kehidupan zooxanthella dan pertumbuhan karang, parameter fisika kimia dilakukan pengukuran saat sampling di setiap titik dapat dilihat pada tabel sebagai berikut :

Tabel 7. Hasil analisis beberapa variabel Fisika Kimia lokasi penelitian

\begin{tabular}{llcccccccc}
\hline \multirow{2}{*}{ No } & Variabel & \multicolumn{7}{c}{ Pengamatan ke } \\
\cline { 2 - 10 } & \multicolumn{2}{c}{$\mathbf{1}$} & \multicolumn{2}{c}{$\mathbf{2}$} & \multicolumn{3}{c}{$\mathbf{3}$} & \multicolumn{4}{c}{} \\
\cline { 2 - 10 } & St-1 & St-2 & St-1 & St-2 & St-1 & St-2 & St-1 & St-2 \\
\hline 1 & Kedalaman $(\mathrm{cm})$ & 150 & 80 & 153 & 84 & 148 & 69 & 151 & 77 \\
2 & Kecerahan $(\mathrm{cm})$ & $\sim$ & $\sim$ & $\sim$ & $\sim$ & $\sim$ & $\sim$ & $\sim$ & $\sim$ \\
3 & Temperatur $\left({ }^{\circ} \mathrm{C}\right)$ & 31 & 31 & 30 & 30 & 30 & 30 & 30 & 30 \\
4 & pH & 7 & 7 & 7 & 7 & 7 & 7 & 7 & 7 \\
5 & Salinitas (\%o) & 30 & 30 & 30 & 30 & 30 & 30 & 30 & 30 \\
\hline
\end{tabular}




\section{PEMBAHASAN}

Laju pertumbuhan karang diukur meliputi tinggi fragmen karang dan lebar fragmen karang dalam setiap pengamatan perbulannya. Laju pertumbuhan karang tinggi dan lebar fragmen karang diukur untuk mendapatkan nilai disetiap bulannya. Spesies Acropora austera didapatkan hasil $0,6 \mathrm{~cm}$ untuk tinggi fragmen karang dan $0,2 \mathrm{~cm}$ lebar fragmen karang, Acropora macrostoma 0,4cm tinggi fragmen karang dan $0 \mathrm{~cm}$ lebar fragmen karang, Acropora nasuta $0,9 \mathrm{~cm}$ tinggi fragmen karang dan 0,1 $\mathrm{cm}$ lebar fragmen karang, Acropora aspera 0,4 tinggi fragmen karang dan $0 \mathrm{~cm}$ lebar fragmen karang. Pengukuran fragmen tinggi dan lebar fragmen karang dilakukan selama 2 bulan dan didapatkan hasil pertumbuhan yang berbagai macam. Pengambilan sampel pengukuran yang diukur dengan karang berukuran tinggi dan lebar fragmennya yang lebih besar. Pada bibit karang yang lainnya hasil ukur tinggi dan lebar fragmen nya berbeda-beda dikarenakan faktor lingkungan sangat mempengaruhi pertumbuhan karang. Beberapa faktor yang sangat mempengaruhi pertumbuhan karang yaitu suhu, kecerahan, kedalaman, salinitas, dan sedimentasi (Rachmawati, 2001).

Pada keempat jenis karang yang ditransplantasikan diperairan Pulau Karimunjawa selama dua bulan pengamatan menunjukan nilai yang berbeda satu sama lainnya. Meski keempat jenis karang tersebut ditransplantasikan bersamaan, karena adanya perbedaan sifat hidup masing-masing jenis karang sehingga dapat juga memicu tingkat tekanan yang berbeda padamasing-masing karangterhadap lingkungan mereka yang baru. Tingkat tekanan inilah yang kemudian mempengaruhi metabolisme karang tersebut untuk dapat beradaptasi.

Kondisi perairan yang berbeda dengan kondisi habitat asal fragmen turut memacu tekanan lingkungan pada karang yang ditransplantasikan. Tekanan lingkungan adalah istilah yang digunakan untuk menjelaskan pengaruh eksternal maupun interval yang dipengaruhi oleh kondisi fisiologis dan aktivitas yang berpengaruh terhadap struktur dan proses-proses dalam populasi, komunitas, dan ekosistem terumbu karang akan mengalami tekanan lingkungan akan mengalami perubahan-perubahan dalam metabolisme, pertumbuhan, respon tingkah laku terhadap lingkungan dan biologi reproduksinya (Arafat, 2005).

Keberadaan alga yang tumbuh disekitar fragmen dapat mempengaruhi tingkat kelangsungan hidup karang. Dalam kedua titik lokasi bagan transplantasi ditemukan banyak bibit karang yang mati selama dua bulan. Dari kedua titik, lokasi bagan transplantasi yang banyak ditemukan mati pada titik satu dikarenakan lokasi yang banyak dilalui oleh kapal nelayan dibandingkan dengan lokasi titik dua. Selama sampling dan pengamatan, banyak bibit karang yang sudah ditumbuhi dengan makroalga terutama pada lokasi titik satu yang mengakibatkan banyaknya bibit karang yang mati seperti spesies Acropora nasuta, Acropora aspera, Acropora macrostoma, Acropora austera.Penelitian-penelitian sebelumnya menunjukkan bahwa makroalga dapat melebihi pertumbuhan karang, dan kompetisi diantara keduanya biasanya dimenangkan oleh alga (Chadwick 1988 ; Hughes 1989 ; in Tanner 1995).

Pada pengamatan terhadap biota disekitar terumbu karang ditemukan berbagai macam biota mulai dari ikan karang hingga bulu babi dikedua titik lokasi penanaman bagan transplantasi karang. Pengamatan pertama dilakukan ketika peletakan bagan transplantasi tidak ditemukan biota disekitar lokasi. Dalam pengamatan kedua disekitar bagan kedua lokasi ditemukan Zanclus sp, Siganus sp, Selaroides sp, dan Diadema sp. Selama lamanya pengamatan dua bulan sudah banyak biota yang ditemukan pada lokasi bagan penanaman transplantasi karang terutama untuk jenis Diadema sp yang pertumbuhan populasinya sangat pesat. Diadema sp banyak ditemukan dilokasi titik dua bisa mencapai 14 buah pada bulan juli dibandingkan dengan waktu pertama peletakan bagan transplantasi karang.

\section{KESIMPULAN}

Kesimpulan yang dapat diambil dari penelitian Aplikasi Biorock Terhadap Kelangsungan Hidup Transplantasi Karang dan Keanekaragaman Ikan di Pulau Karimunjawa adalah sebagai berikut:

1. Kelangsungan hidup dan pertumbuhan rata-rata karang yang ditransplantasi pada biorock, Acropora austera 33,33\%, Acropora macrostoma 24,99\%, Acropora nasuta 49,9\%, Acropora aspera 41,66\%.

2. Jumlah spesies ikan yang berada disekitar biorock adalah 3 spesies. Spesies Moorish idol, Selaroides, Sigans canaliculatus. Sedangkan jenis lain yang ditemukan adalah Diadema sp. Jumlah ikan yang ditemukan adalah Zanclus sp 21, Selaroides sp 22, Siganus sp 19, sedangkan Diadema sp 37.

\section{UCAPAN TERIMAKASIH}

Ucapan terimkasih ditunjukan kepada Prof. Norma Afiati, M.Sc., Ph.D dan Nurul Latifah, S.Kel, M.Si yang telah memberikan saran dan kritik yang bermanfaat bagi penulis. Kepada semua pihak yang telah membantu sehingga penulis dapat menyelesaikan artikel ini. 


\section{DAFTAR PUSTAKA}

Arafat D. 2005. Tingkat Kelangsungan Hidup dan pertumbuhan Karang (Hydnopora rigida dan Lobophyllia hembprichii) hasil fragmentasi buatan pada bak terkontrol (Skripsi). Departemen Ilmu dan Teknologi Kelautan, Fakultas Perikanan dan Ilmu Kelautan, Institut Pertanian Bogor. Bogor. 78 hlm.

Balai Taman Nasional Karimunjawa, 2012. Zonasi taman Nasional Karimunjawa Tahun 2012. Direktorat Jenderal Perlindungan dan Konservasi Alam Balai Taman nasional Karimunjawa. Revisi Zonasi Taman Nasional Karimunjawa. 91 hal.

(COREMAP) Coral Reef Management Project II, 2008. Buletin COREMAP II Provinsi Sumatra Utara: Mediterm Review ADB. Edisi ke-3. Dinas Kelautan dan Perikanan Provinsi Sumatra, Medan.

Nazir. 1988. Metode Ilmiah. Jakarta : Ghalia Indonesia.

Rachmawati R. 2001. Terumbu Buatan (Artificial Reef). Pusat Riset Teknologi Kelautan Badan Riset Kelautan dan Perikanan Departemen Kelautan dan Perikanan Republik Indonesia. Indonesia. $50 \mathrm{hlm}$.

Tanner JE. 1995. Competition between scieretinian corals and macroalgae : An experimental investigation of coral growth, survival and reproduction. J. Exp. Mar. Biol. Ecol. 190:151-168.

Wuzurai, P., S. Redjeki, dan S.T. hartati, 2012. Studi Kelimpahan Juvenil Ikan pada Ekosistem Padang lamun di Perairan Karimunjawa, Kabupaten Jepara. Journal of Marine Research1(2). 